\title{
MODOS DE VIDA DE AGRICULTORES FAMILIARES DE MONTANHA: UM ESTUDO DE CASO EM SÃO PEDRO DA SERRA - NOVA FRIBURGO - RJ
}

\author{
Maria José Carneiro ${ }^{1}$ \\ Juliano Luís Palm²
}

\section{Modo de vida: $o$ conceito}

Abordagens sustentadas na noção de modos de vida remonta a meados do século $\mathrm{XX}^{3}$, quando, em uma perspectiva transdisciplinar, esta categoria passou a influenciar os estudos etnográficos sobre campesinato e o pensamento e práticas acerca do desenvolvimento rural (Chambers e Conway, 1992). Neste contexto, destaca-se no Brasil, Antonio Candido, um dos pioneiros nesta abordagem, com sua tese defendida em 1954, Os parceiros do Rio Bonito: estudo sobre o caipira paulista e a transformação dos seus meios de vida ${ }^{4}$.

Apesar das contribuições dos trabalhos em diálogo com a perspectiva modos de vida, o "contexto dominado pelas abordagens da teoria da dependência e neo-marxitas" (Schneider, Souza e Pereira, 2010: 213) no período posterior à Segunda Guerra Mundial, não foi favorável ao desenvolvimento de análises sustentadas nessa abordagem. Todavia, observa-se que as pesquisas sobre os modos de vida no meio rural, sobretudo na Antropologia, tiveram continuidade, tomando a forma de "estudos de comunidade", muito marcados pelos dois estudos clássicos de Robert Redfield, The Little Community and Peasant Society and Culture, cuja primeira edição, em um só volume, data de 1956. No Brasil, Maria Isaura de Queiroz inaugura uma linha de pesquisa que passou a agregar os primeiros estudiosos do tema no Centro de Estudos Rurais (1964), posteriormente, Centro de Estudos Rurais e Urbanos (CERU-USP).

\footnotetext{
${ }^{1}$ Universidade Federal Rural do Rio de Janeiro, Brasil.

${ }^{2}$ Universidade Federal de Santa Maria e Universidade Federal Rural do Rio de Janeiro, Brasil.

${ }^{3}$ Outros autores avançam ainda mais no tempo, remetendo a genealogia desta categoria ao século XIX. Como pontuam Schneider, Souza e Pereira, para Haan "a primeira versão do que hoje seria a perspectiva 'livelhoods' à noção de 'genre de vie' introduzida por Vidal de la Blache no século XIX" (2010: 213).

${ }^{4}$ Para o aprofundamento da discussão acerca da relação entre o conceito desenvolvido por Candido e os desenvolvimentos atuais de "livelihoods", ver Schneider, Souza e Pereira (2010).
} 
A perspectiva dos modos de vida voltaria a ganhar lugar de destaque, principalmente na sociologia rural, atrelada à discussão sobre o desenvolvimento rural, a partir da década de 1990, em reposta às críticas às abordagens "de cima para baixo", de "fora para dentro". A partir de então, passaram a ganhar força abordagens orientadas aos atores sociais, numa perspectiva "de baixo pra cima", em que o desenvolvimento rural passou a ser visto como um processo necessariamente participativo, envolvendo a perspectiva dos atores sociais no controle e escolha de suas prioridades. Assim, as inovações de tecnologias agrícolas deveriam partir das experiências dos agricultores envolvidos. Em um contexto marcado pelo recrudescimento dos movimentos de crítica à Revolução Verde, a abordagem dos modos de vida passou a ganhar novo fôlego, em contraposição às abordagens que limitavam suas análises aos processos agrícolas.

Autores como Ellis (2000) e Scoones (2009) concordam que os estudos recentes dos modos de vida tiveram sua inspiração no conceito proposto por Chambers e Conway (1992) que levava em conta tanto os recursos naturais (terra e água, sobretudo) como a reivindicação e o acesso a alimentos e roupas como elementos a partir dos quais as pessoas constroem seu modo de vida valendo-se de seu trabalho físico, habilidades e saberes. Em diálogo com Amartya Sen (2010), Chambers e Conway (1992) recorrem à noção de "capacidade" dos indivíduos de levarem a vida desejável como um direito e, ao mesmo tempo, numa perspectiva instrumental, como um vetor do desenvolvimento econômico.

Outras duas noções compõem o conceito de modo de vida desses autores: equidade e sustentabilidade. A primeira se refere à necessidade distribuição dos bens, capacidades e oportunidades de maneira menos desigual. Com este conceito os autores buscavam se contrapor às abordagens que se prendem às dimensões da privação advindas do pensamento de países industrializados, a exemplo da noção de "linha da pobreza". Na compreensão dos autores esse tipo de abordagem não dariam conta de apreender as realidades complexas e diversificadas do meio rural. Por fim, o conceito de sustentabilidade é utilizado pelos autores em dois sentidos: externamente, referindo-se ao impacto que um modo de vida pode gerar sobre os demais, seu efeito sobre os recursos locais e globais e, internamente, referindo-se à capacidade de um modo de vida de suportar pressões externas mantendo sua capacidade de continuar e aumentar os 
ativos. Nessa perspectiva, sociedade-natureza são interdependentes, interconectados e indissolúveis. ${ }^{5}$

Para os propósitos deste artigo, recorremos à noção de modo de vida como chave analítica para apreender o processo histórico de conformação de uma forma de viver sustentada na agricultura familiar em dois distritos do município de Nova Friburgo, na região serrana do Rio de Janeiro: como neste processo os sujeitos foram garantindo suas necessidades, adaptando-se e resistindo aos condicionamentos advindos da sociedade e da relação com a "natureza".

\section{O processo histórico de conformação de um modo de vida}

O município de Nova Friburgo localiza-se entre duas bacias hidrográficas: Macaé e Paraíba do Sul, o que lhe confere uma importância estratégica destacada na manutenção dos mananciais que abastecem os municípios situados na jusante. Nova Friburgo apresenta 92\% de sua área dentro do domínio da chamada Mata Atlântica, o que a transforma em objeto de controle ambiental que atua como instrumento inibidor da atividade agrícola. Por apresentar essas características, essa região atraiu iniciativas preservacionistas que resultaram em duas Áreas de Preservação Ambiental Municipais - Rio Bonito de Cima e Macaé de Cima - além de duas Unidades de Conservação de Estaduais: Parque Estadual de Três Picos e APA Estadual de Macaé de Cima. Esta última abrangendo os territórios dos distritos São Pedro da Serra e Lumiar, onde foi realizada a presente pesquisa.

Na segunda década do século XIX, Dom João efetivou o primeiro projeto oficial de colonização com imigrantes europeus não portugueses. Em 1819 os primeiros 1631 imigrantes, originários do Cantão de Friburgo, na Suíça, desembarcaram no porto do Rio de Janeiro, sendo logo encaminhados ao núcleo de residências construído para abrigá-los na fazenda Morro Queimado, dando origem ao município de Nova Friburgo. Em 1824 viriam a somar-se a estes uma nova leva de migrantes, desta vez, alemães.

Pelas dificuldades encontradas por estas levas de migrantes na região em que foram alocados, com topografia extremamente acidentada, dificultando a agricultura e a comunicação entre os lotes e os centros urbanos, além da ausência de uma administração eficaz, muitos partiriam em busca de terras melhores. Dessa dispersão,

\footnotetext{
5 Schneider, Souza e Pereira (2010) salientam ser este um aspecto que aproxima a compreensão de "livelhoods" à de meios de vida desenvolvida por Antonio Candido.
} 
resultou a ocupação da região que hoje é formada pelos distritos de Lumiar e São Pedro da Serra (Nicolin, 1995; Curió, 1974).

$\mathrm{O}$ constante deslocamento em busca de terras mais apropriadas à agricultura deixou expressivas marcas na trajetória dessas famílias de migrantes, podendo ter sido responsável pela ausência de uma identidade centrada na origem étnica, como também pela curta memória genealógica que marcam o modo de vida desta população. Apesar da predominância de traços fisiológicos (pele clara, olhos azuis, cabelos alourados) e dos nomes de família que remontam a migração germânica e suíça, os descendentes desses colonos não se reconhecem como sendo distintos dos demais habitantes brasileiros que compartilham com eles a história da ocupação desse território, como também não recorrem à essa origem para justificar suas práticas contemporâneas, como ocorre entre os descendentes de migrantes da Região Sul do país (Carneiro, 2000). Com a atração de imigrantes europeus para regiões de terras "disponíveis" 6 objetivava-se o branqueamento racial; a ocupação de 'vazios demográficos'; a valorização fundiária destas terras, a disseminação de técnicas e produtos praticados na Europa; além da vinculação da produção oriunda destas regiões aos circuitos mercantis estabelecidos, criando um centro policultor para garantir o abastecimento da Corte (Muaze, 2008; Petrone, 1982). Com estes objetivos foram distribuídas sementes de centeio, trigo e cevada para os migrantes, como também tentou-se o cultivo de uva na região. Contudo, a precariedade e a instabilidade marcaram os modos de vida desses imigrantes desde sua origem até recentemente. Considerando as dificuldades encontradas e a ausência de uma infraestrutura já estabelecida, esses colonos passaram por um processo forçado de adaptação conhecido como "caipirização", termo utilizado por Hebe de Castro para caracterizar os lavradores da região vizinha, Capivari, hoje município de Silva Jardim (Castro, 1987). Esses colonos e seus descendentes enfrentaram uma situação que em nada diferia da dos demais camponeses pobres da região, não chegando a produzir um excedente capaz de permitir investimentos seja na produção seja na melhoria das condições de vida. Desta forma, logo passaram a adotar as mesmas práticas agrícolas dos demais camponeses, cujo exemplo mais expressivo é o sistema de pousio ${ }^{7}$, herança deixada pelos povos indígenas e que se tornou a base do manejo agrícola realizado nesta região a partir de então (Costa, Turetta, Donagemma e Balieiro, 2010).

\footnotetext{
${ }^{6}$ Terras tidas como "disponíveis" pelo Governo e pelas empresas privadas de colonização na realidade já eram habitadas por povos indígenas e, talvez, grupos quilombolas, neste período (Araújo e Mayer, 2003).

${ }^{7} \mathrm{Ou}$ "descanso da terra", conforme é conceituado este manejo no linguajar nativo.
} 
Ocupando um espaço econômico marginal, nas franjas das grandes fazendas de café, esses migrantes foram desenvolvendo uma agricultura de pequena escala, incapaz de garantir a reprodução estável e ampliada de suas famílias. De meados do século XIX ao início do século XX, dedicaram-se ao cultivo de café combinado a outros produtos para o consumo próprio das famílias ou trocas internas, a exemplo do feijão, mandioca, hortaliças e a criação de animais.

Essa produção agrícola bastante diversificada, o suficiente para garantir certa autonomia das famílias em relação ao consumo de alimentos, não excluía a produção mercantil que tinha no café e na carne de porco os principais produtos. Os alimentos consumidos e não produzidos eram obtidos através de um circuito de trocas intercomunitárias que também compunham as relações de sociabilidade. De acordo com os relatos dos moradores mais antigos, a vida comunitária era intensa com pouca interferência de elementos externos. Os espaços de sociabilidade se distribuíam em círculos concêntricos que incluíam o espaço doméstico, o círculo de vizinhança e a comunidade.

Com a decadência da lavoura de café, aprofundada nas primeiras décadas do século XX (Fragoso, 2003), ocorreu uma redefinição dos cultivos agrícolas na região ${ }^{8}$. A partir de então, os agricultores passaram a aliar a produção para o autoconsumo a produtos voltados para a comercialização nos centros urbanos, com ênfase na lavoura de inhame (Rego, 2008; Teixeira, 1998; Carneiro e Teixeira, 2004). Contribuiu, para isso, a abertura de uma estrada (Lumiar-Mury), no final dos anos 1950, que encurtou a ligação com a sede do município. Até então, o escoamento da produção era realizado por meio de tropas de burros, que levavam cerca de três dias para chegarem à cidade de Nova Friburgo.

Com a melhoria da comunicação rodoviária houve uma intensificação das relações com o mercado, aumentando o consumo de produtos industrializados, tanto no que se refere à produção como ao próprio consumo, reduzindo o sistema de trocas que ainda vigorava entre as famílias de agricultores. A generalização das trocas mercantis contribui também para intensificar a diferenciação social com base na propriedade de meios de comercialização. Aqueles que possuíam animais de carga no passado, deram lugar aos proprietários de veículos motorizados que assumiram o papel de

\footnotetext{
${ }^{8}$ Apesar de alguns pés de café resistirem até o início da década de 90 , a importância mercantil desse produto não resistiu à crise dos anos 30 .
} 
atravessadores, se firmando como único meio de escoamento da produção local (Carneiro, 2012). Verificou-se também o início da chegada de agrotóxicos e novas variedades de sementes e mudas, introduzindo os agricultores no processo de modernização que marcou a agricultura brasileira, principalmente, a partir da década de 1960. Contudo, o pacote tecnológico da Revolução Verde encontrou limites à sua difusão, especialmente pelas características topográficas da região o que dificultou a mecanização e contribuiu para a manutenção de uma agricultura de pequeno porte e menos devastadora do meio ambiente.

Na terra fria [área montanhosa] o trabalho é muito mais pesado, tu não tem como botar máquina pra fazer as coisas como na terra quente [áreas planas e de menor elevação], porque aqui é tudo morro (agricultor de Lumiar).

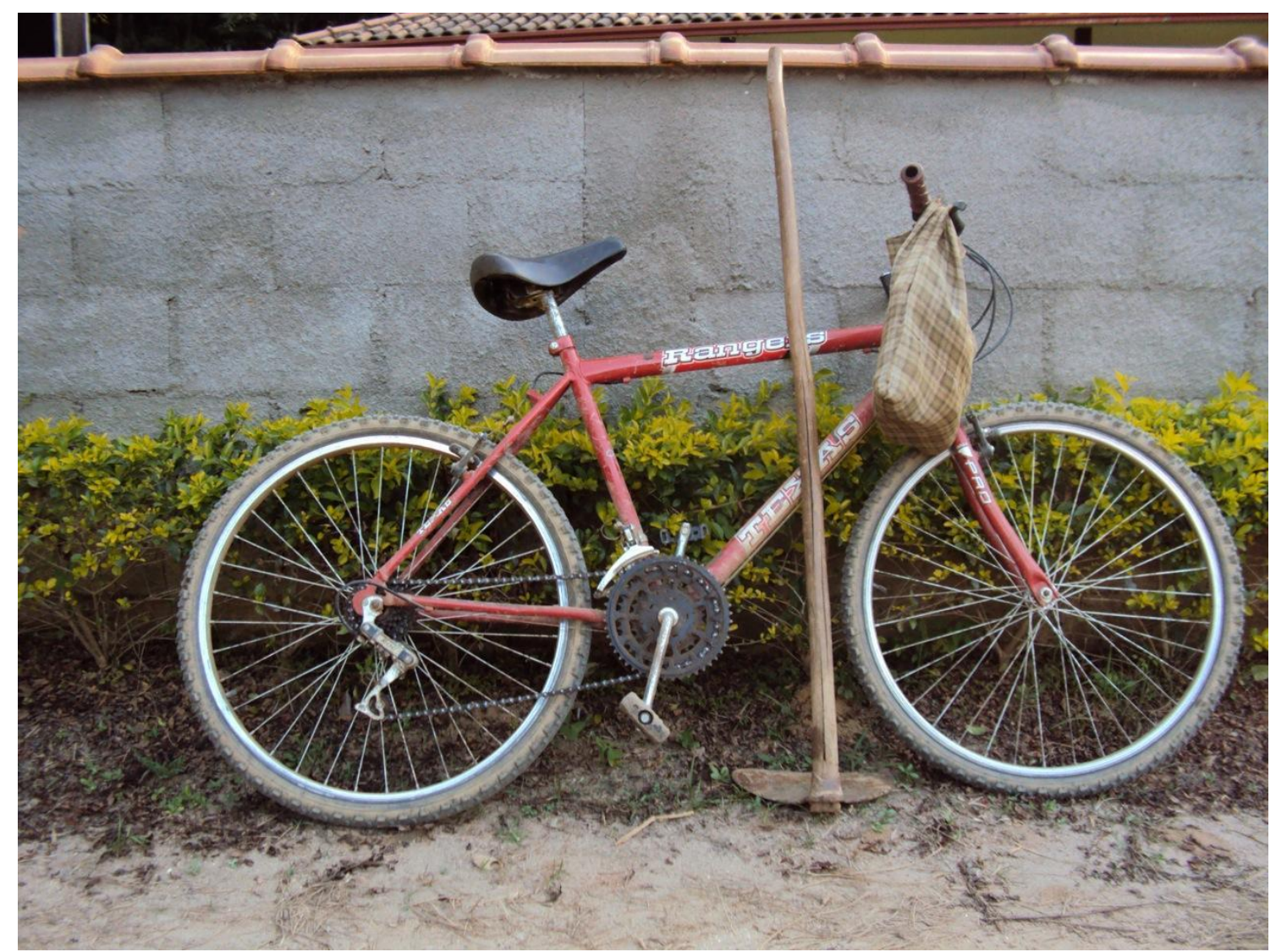


Os reflexos do intenso desmatamento realizado nas regiões em que se expandiram as grandes fazendas de café, vizinhas aos distritos de São Pedro da Serra e Lumiar, posto em curso a partir de inícios do século XIX, ainda podia ser claramente observado em meados do século XX, conforme é destacado no relatório referente ao município de Bom Jardim, na Enciclopédia dos Municípios Brasileiros ${ }^{9}$ :

O revestimento florístico da região é representado apenas por capoeiras e capoeirões, resultado do devastamento das matas, em épocas remotas, para o plantio do café. É, pois, o município pobre em sua vegetação, muito embora ainda encontrem-se algumas madeiras de lei, como cedro, camélia, peroba, ipê, jequitibá e variedades de plantas medicinais e frutos oleaginosos (IBGE, 1959: 206).

Em pesquisas recentes, técnicos da Empresa Brasileira de Pesquisa Agropecuária (EMBRAPA, 2010) atribuem à prática do pousio a responsabilidade pela preservação das florestas na região qualificando esse tipo de manejo como mais adequado e sustentável para áreas de montanha.

O pousio consiste em deixar em repouso (sem lavoura), alternadamente, o solo de pequenas áreas ( 3 a 5 hectares), por um período de tempo que varia entre 4 a 10 anos. Durante este período ocorre o desenvolvimento gradual da vegetação de capoeira, podendo formar, ainda, uma floresta secundária mais avançada, que é essencial para a incorporação de nutrientes no solo. Depois de período, a vegetação é cortada e a terra trabalhada para o plantio. O desenvolvimento desta vegetação tem a capacidade de ampliar a regeneração do solo de uma forma gradual, natural e espontânea, permitindo a regeneração da vegetação nativa, a partir das sementes e brotações remanescentes no solo ou trazidos pelo vento e animais (Costa, Silva, Salgado, Bertolino e Barros, 2009). Também pesquisadores da EMBRAPA concluíram que esse tipo de manejo seria mais adequado para áreas de montanha e da Mata Atlântica, pelo seu caráter conservacionista (Costa, Turetta, Donagemma e Baileiro, 2010: 4). Mas, como veremos abaixo, essa prática está sendo abandonada devido a imposições da legislação ambiental que restringe enormemente o corte da vegetação.

\footnotetext{
${ }^{9}$ IBGE. Enciclopédia dos Municípios Brasileiros. Volume XXII. Rio de Janeiro, 1959. Documento encontrado no arquivo do Instituto Histórico e Geográfico Brasileiro, sediado na capital do estado do Rio de Janeiro.
} 


\section{Hábitos alimentares, pluriatividade e identidade social: novas dinâmicas}

Melhorias nas condições de acesso à São Pedro da Serra e Lumiar, a partir da década de 1980, desencadearam uma nova dinâmica no modo de vida local. Os principais vetores dessa mudança são a intensificação das atividades do setor de turismo e o direcionamento da produção agrícola para o mercado atacadista do Rio de Janeiro e de Nova Friburgo.

A crescente atração de turistas para a região acarretou certa reelaboração da identidade social local, a partir da conformação de novas redes sociais, novos valores e motivações, por meio da interação com sujeitos oriundos de outros universos sociais e simbólicos. Por outro lado, esse processo contribuiu também para a reafirmação de determinados traços do modo de vida da população desta região, em grande parte vinculados a sua trajetória histórica. Assim, passaram a ser afirmadas as clivagens entre os "da terra" (os nativos), e os "outros", ou "de fora".

Ter nascido na região, não dar importância para as baixas temperaturas que a assolam no período de inverno, ter força para a realização de serviços braçais "pesados", são algumas das características recorrentemente afirmadas pelos sujeitos locais como expressivas daqueles que são "da terra". Todavia, nascer ou residir na região há anos e possuir as qualidades acima, não são suficientes para demarcar as fronteiras entre os que são "da terra" e os "de fora". O principal elemento levado em consideração são os laços familiares que remetem ao processo de ocupação histórica da região. Um morador que reside na localidade há quase trinta anos, participando ativamente do cotidiano local, tendo desenvolvido intensas relações de amizade e de vizinhança, seria um "quase da terra":

se eu tivesse me casado com uma mulher das famílias tradicionais da região, constituído família com ela, talvez, hoje, eu já seria 'da terra'. Mas, como eu sou casado com alguém que também é 'de fora', eu posso ser, no máximo, 'quase da terra' (risos).

Com o acirramento da questão ambiental, aprofundada a partir da década de 1990 com a intensificação do implementação da legislação, os "de fora" passaram a ser subdivididos entre "bons" e "maus", na concepção da população local. Os "bons" visitam a região e "trazem muitas coisas boas", contratando pessoas do local para trabalharem em seus sítios e residências e realizando compras no comércio local. Já os 
"maus" são aqueles que "castigam o povo da terra", principalmente fazendo denúncias aos órgãos ambientais sobre as práticas agrícolas "tradicionais" agora consideradas ilegais pela legislação ambiental, como o corte da capoeira e queimada dos tocos. Nesse grupo estão inseridos os "turistas" que, identificados com os ideais preservacionistas, desenvolvem uma valoração negativa da atividade agrícola. Esta percepção ancora-se no "mito moderno da natureza intocada" (Diegues, 2001) contribuindo para reforçar uma clivagem entre os ambientalistas e os agricultores. Enquanto o agricultor percebe um espaço coberto pela vegetação secundária como uma área de lavoura em potencial, qualificando-a como "capoeira", ou área em "descanso", esses outros - turistas e agentes ambientais - classificam a mesma vegetação como "mata em regeneração". Voltaremos a esse assunto mais tarde.

A dinamização do setor de turismo e a intensificação da lavoura mercantil aumentaram a quantidade e a circulação da moeda provocando transformações no modo de vida local tais como a preferência por alimentos industrializados de fácil preparo, mais adaptados ao novo ritmo de trabalho (não-agrícola) e às mudanças dos hábitos alimentares promovidas por uma nova concepção de saúde divulgada pelos médicos (substituição da gordura de porco pelo óleo vegetal, consumo de legumes e verduras...). Contribuiu também para essa "nova economia", a substituição do manejo tradicional da agricultura pelo uso de sementes e insumos agrícolas químico-sintéticos adquiridos no mercado.

Essa nova realidade afetou também a vida das mulheres que se viram dispensadas de certas tarefas domésticas. A necessidade e a facilidade da comercialização, tanto da produção como do consumo, atraíram as famílias de agricultores para perto dos estabelecimentos comerciais o que, junto com a exploração turística, provocou um crescimento da "rua" - a sede "urbana" do distrito. Esse adensamento de famílias acarretou o abandono da criação de quintal, já que as casas são construídas em pequenos lotes, muito próximas uma das outras e distantes dos sítios de lavoura, o que desobrigou a mulher de suas tarefas produtivas na roça e no quintal, liberando-a para trabalhar em atividades remuneradas não-agrícolas, como empregadas domésticas ou faxineiras nas casas de turistas e pousadas, contribuindo, assim, para aumentar a renda familiar. A monetarização das relações de trabalho e a facilidade de se adquirir alimentos no comércio local, também contribuíram para o relativo abandono da produção agrícola para o autoconsumo, por parte de algumas famílias. Contudo, apesar 
das transformações ocorridas nos hábitos alimentares, observa-se, contraditoriamente, a valorização da alimentação do passado, no sentido inverso do que seria considerado "saudável” pelos novos padrões nutricionais. Considera-se que, antigamente, a comida era "mais pura" e "mais saudável" porque não continha "química". A referência à "pureza" como definidora de comida saudável serve, como chama a atenção Brandão (1981), para se estabelecer diferenças e avaliações sobre o modo de vida do passado e o de "hoje em dia". "Antes todo mundo só comia gordura de porco e ninguém tinha colesterol" porque "a pureza da carne está na alimentação do animal", explica um agricultor. A "carne boa" é aquela que é alimentada com "comida da roça", "lavagem" para porco. "O porco era engordado só com produtos que se colhia, não gastávamos nada, não dava ração. O porco era "saudável, orgânico". Hoje é totalmente diferente, em dois meses o animal já está em ponto de abate", avalia um jovem agricultor criador de suínos. Estabelece-se assim uma hierarquia entre os alimentos e as carnes, em particular, com base no grau de artificialidade no processo de criação/produção e da ausência de controle do consumidor sobre esses cuidados. As carnes de porco e a de gado criados na roça eram mais saudáveis, porque os animais recebiam comida "limpa", comenta uma antiga moradora, que também não come "carne de açougue", porque ouviu na televisão que dão "vacina" nos bois, e não come frango congelado porque não sabe de quê ele morreu.

A comida saudável também é avaliada segundo o circuito percorrido pelo alimento até a mesa do consumidor. A "vitalidade" dos alimentos está relacionada à ideia da comida "fresquinha", que "se come na hora que colhe", como o aipim presente nas refeições de quase todos os dias. $\mathrm{O}$ alimento do supermercado fica exposto durante muito tempo, além de levar outro tempo até chegar ao mercado, o que faz com que perca sua "vitalidade", fica "velho". Já o alimento da roça tem mais qualidade, porque é "fresquinho". Podemos entender, assim, que o alimento "fresco" guarda os componentes que contribuem para manter a saúde do homem, como também guarda mais sabor.

Alguns agricultores mais jovens têm uma compreensão de "alimentação saudável" que combina os valores transmitidos pelos pais, sustentados na valorização do trabalho camponês, com os valores da sociedade moderna adquiridos quer seja na escola quer seja pela mídia ou pela relação com os novos residentes. Falam do orgulho que têm de comerem o que produzem, não só porque é fruto do seu trabalho, mas 
também por considerarem que esse alimento é mais "saudável" do que o comprado no mercado. Entretanto, ao lado dessa avaliação, reconhecem também os riscos do "colesterol" e da necessidade de se comer sempre "salada" e "legumes" para contrabalançar. A comida "balanceada", explica um jovem agricultor que é também professor de uma escola local, "deve ter muita variedade no prato, sete ou oito qualidades, um produto intera com outro e a comida fica balanceada".

Mas essa "receita" parece falar de um ideal raramente colocado em prática. A comida do dia-a-dia é a comida "possível", aquilo que está disponível na lavoura em cada período do ano, complementado com o que se ganha através das trocas entre vizinhos e parentes e com o que se pode comprar no mercado. Soma-se a esses ingredientes o critério da praticidade, a comida deve ser "rápida" de preparar, mas deve conter os alimentos "fortes" para sustentar o trabalhador por toda sua jornada de trabalho. A combinação dos "produtos da roça" com algum "manufaturado", comprado, produz um cardápio rico em carboidratos e com alguma proteína. Arroz, macarrão, feijão e algum tubérculo (aipim, inhame ou batata baroa) estão quase sempre presentes. Acrescenta-se alguma verdura (repolho ou almeirão) e, às vezes, a "mistura": linguiça, salsicha ou algum tipo de carne.

Essa dieta, contudo, vai variar com a idade, pelo menos idealmente. As pessoas mais idosas, que não trabalham mais na lavoura, devem comer em menor quantidade e alimentos considerados menos "pesados", evitar carnes em geral e a gordura de porco. Diferente do pessoal que trabalha na lavoura, que pode (e deve) comer comida "pesada", que "sustente" e que, nesse caso, não faz mal à sua saúde. Já os idosos devem alimentar-se de "verduras" e "comida da roça": inhame, repolho, batata, feijão que às vezes é cozido junto com a beterraba. A força dos alimentos está relacionada ao sabor, ao gosto forte, e à sustância. Nem só o que tem "proteína" é considerado "forte". Os produtos "da terra", que sempre foram cultivados e alimentaram os lavradores e suas famílias por gerações, também são considerados "fortes". É o caso do aipim, do inhame e da abóbora.

Uma demonstração da "força" desses alimentos é a "broa de planta", uma receita antiga que misturava todos esses "produtos da roça" e os temperos, que podiam ser salgados (toucinho, sal, pimenta) ou doces (açúcar, canela e erva-doce). Fazia-se uma massa, enrolava-se na folha de bananeira e assava-se no forno de barro. Serviam de alimento para os agricultores que as levavam para a roça, já que não podiam retornar 
para comer em casa, devido à distância. No entanto, apesar das nostálgicas referências ao sabor dessas broas, elas não são mais preparadas, o que é justificado, por alguns, pela inexistência de fornos a lenha e pelo trabalho necessário ao preparo.

Há um consenso de que as mudanças dos hábitos alimentares e das práticas agrícolas trouxeram problemas de saúde que não existiam antes, apesar de ter havido uma ampliação da diversidade do que se come e do que se planta. Se, de um lado, essa mudança é encarada como positiva, sobretudo na praticidade de se ter "tudo para comprar" e pela variedade disponível, de outro, é vista como negativa, quando se pensa na qualidade, como exemplifica a observação de um agricultor:

Não adianta comprar no mercado porque tudo que se compra lá também tem veneno. O quê que não tem veneno? Até galinha e carne de gado tem veneno. O leite de caixa também é ruim, botam o mesmo remédio que botam nos cadáveres. Tem um cheiro horrível e não estraga. O leite de vaca, se você bobear, ele estraga e o de caixa não. Só a cerveja não tem veneno [brinca rindo da sua própria sorte].

A comida no passado era completada também com alimentos extraídos da mata. "Antigamente tiravam muita coisa da mata para comer: palmito, buta (um cacho como o de uva) que era muito gostoso de chupar, meio amargo. Hoje, eles colocam na cachaça. Comia também broto de bambu, broto de samambaia, olho de bananeira, broto de abóbora... tudo minha mãe fazia", lembra um jovem chefe de família, que há alguns abandonou o trabalho na construção e retornou à lavoura. Todavia, após alguns anos plantando em parceria com os cunhados na terra de um grande produtor para os padrões locais, abandonou novamente a lavoura, voltando para a construção civil, porque estava se sentido mal, "muito nervoso", o que atribuiu ao "veneno", o agrotóxico.

A massiva aplicação de agrotóxicos atualmente (enquanto no passado isso não ocorria) é atribuída à mudança dos produtos plantados hoje em dia. No passado plantavam-se os "produtos da roça", ou "da terra", e em "pequena quantidade", enquanto que hoje é necessário plantar muito para conseguir vender no Ceasa e ter algum retorno financeiro. Além disso, atualmente plantam produtos que "vêm de fora", "sementes híbridas", que exigem cuidados especiais. Reconhecem, também, que para conseguirem um bom preço é preciso oferecer uma "boa qualidade", os frutos têm de ser "bonitos", o que não se consegue sem "engordar a terra" com os adubos químicos, e sem a utilização de "remédios" ou "venenos" para combater as "doenças". Entendem que se não recorrerem aos agrotóxicos, as sementes "não vingam", “degeneram", 
porque não são "da terra" ${ }^{10}$. O mesmo acontece quando se tenta replantar sementes retiradas da lavoura. "Se você for na lavoura e tirar semente desse tomate (de semente comprada) que você plantou, vai nascer um tomate muito degene..., como se diz, muito menorzinho. Em vez de sair aquele tomatão bonito, vai sair aquela coisa miudinha", explica um agricultor. A noção de "degeneração" é recente, mas parece ter sido rapidamente assimilada pelos agricultores, por força de suas próprias experiências e, certamente, do discurso dos vendedores dos insumos químicos e de um ou outro técnico agrícola, em uma das raras visitas ao local.

As lavouras para fins exclusivamente comerciais, como o tomate, o pimentão, a couve-flor, a berinjela e a abobrinha, são as que mais "exigem" as técnicas convencionais de plantio. Já os "produtos da roça" - inhame, aipim, batata baroa, batata-doce - que servem alternativamente para o consumo e para a venda - não requerem o uso de agrotóxicos, ou exigem menos. São considerados mais resistentes às pragas, por serem "daqui mesmo", servindo também para "limpar" o terreno das pragas comuns em outros produtos e recuperar parcialmente a fertilidade do solo, quando plantados no sistema de rodízio. "Eu faço rodízio de lavoura, porque o terreno é pequeno, não é muito grande para deixar encapoeirar, "descansar", como se diz. Aí a gente troca de lavoura. Aonde tem couve-flor coloca (batata) baroa ou, senão, inhame e bota a couve (-flor) em outro terreno aonde já tinha baroa", explica um agricultorfeirante, proprietário de alguns pequenos "sítios" de lavoura na região. Seu filho, solteiro, que trabalha com ele, acrescenta: "porque nem toda lavoura consome os mesmos nutrientes da terra".

Já os produtos orientados para o mercado exigem um cuidado especial, são mais suscetíveis às pragas e doenças e as sementes são adquiridas em lojas especializadas na cidade de Nova Friburgo. O imperativo de comprar sementes selecionadas é atribuído à necessidade de se plantar em grande quantidade para vender no atacado e ao fato de serem sementes selecionadas, isto é, que não são "da terra". Como comenta um agricultor da região:

\footnotetext{
${ }^{10}$ Podemos entender a expressão "sementes da terra" de duas maneiras: sementes que são nativas do lugar, ou que são tidas como tal porque fazem parte da tradição agrícola do lugar; e sementes que ficam dentro da terra, ou seja, raízes, e, por isso seriam menos suscetíveis a insetos e pragas.
} 
Todas (sementes) são compradas porque são selecionadas, você não tem como fazer isso na lavoura. As sementes hoje em dia são tudo modificadas, são geneticamente modificadas, então você não tem como selecionar na lavoura. Às vezes você seleciona uma ou duas. Se você tirar 100 de uma lavoura, daquelas 100 só 10 vão ser perfeitas, o resto tudo não vai prestar.

Uma consequência negativa desse processo histórico de inserção da agricultura regional aos mercados, extremamente aprofundado nas últimas décadas, é a perda do controle sobre as mudas e sementes por parte do agricultor. Plantas e sementes selecionadas ao longo da trajetória histórica da agricultura familiar da região foram se perdendo, em vista da disseminação de mudas e sementes modificadas que foram sendo incorporadas para atender as demandas mercantis. $\mathrm{O}$ agricultor justifica essa perda pela exigência do mercado, atribuindo a responsabilidade ao consumidor que não aceita produtos menores ou imperfeitos como eram os produtos da lavoura tradicional. Todavia, salientam que os produtos "de antigamente" eram bem mais saborosos. Da mesma forma, reconhecem que a adesão aos insumos químicos e inseticidas foi, em grande parte, devida às exigências de mercado. "Antigamente não precisava agrotóxicos. Começaram a usar pro negócio ir mais rápido, o que hoje tem que ser", lembra outro agricultor da região.

Essa dependência ao mercado se reflete na elevação dos custos da produção, aumentando a instabilidade da maioria dos pequenos agricultores, como já apontamos acima. Principalmente daqueles que não são proprietários e que se veem obrigados a arcar com o investimento feito na lavoura além do pagamento pelo uso da terra, o que pode levar ao abando da atividade agrícola por parte dos agricultores ou, alternativamente, a combiná-la com atividades não-agrícolas. Assim, a agricultura foi perdendo espaço como principal fonte de renda econômica e de inserção social das famílias de agricultores locais (Teixeira, 2001 e 2004), mas permanece ainda como marca identitária de muitas famílias e mesmo da própria localidade.

A dinamização de atividades não-agrícolas na região, em sua grande maioria vinculadas à expansão do turismo (jardinagem, limpeza e, construção de casas para aluguel, restaurantes, pousadas e comércio em geral), ocorre em um contexto que não leva necessariamente ao desaparecimento da agricultura. Ao contrário, observa-se a disseminação da combinação de atividades agrícolas com não-agrícolas, ampliando o campo de atuação possível à população local com reflexos na permanência da agricultura (Carneiro e Teixeira, 2004; Teixeira, 2001; Teixeira 2004). Essa múltipla 
inserção econômica pode ocasionar um alargamento do universo social do agricultor pluriativo, com a conformação de novas redes sociais, novos valores e motivações, sobretudo entre os jovens.

Neste sentido, observa-se que a ampliação da definição do que venha a ser agricultor, desvinculando esta categoria do seu conteúdo meramente produtivo, coloca em cena a questão da identidade social. Por outro lado, com a ampliação do mercado de trabalho não-agrícola observa-se um desestímulo à agricultura, sobretudo do jovem que não quer mais se submeter ao ritmo de trabalho exaustivo, considerado pesado e desgastante, além de oferecer uma baixa remuneração em comparação a outras alternativas locais (confecção de roupas íntimas, comércio, e construção civil). Em um conjunto de entrevistas realizadas com 49 agricultores dos distritos de São Pedro da Serra e Lumiar, entre os meses de dezembro de 2012, janeiro e fevereiro de 2013, observou-se que a faixa etária do universo de agricultores da região concentra-se entre os 40 e 70 anos, com apenas dois entrevistados abaixo dos 30 anos e outros dois entre 30 e 40 anos de idade ${ }^{11}$. Além dessas fatores, há de se levar em conta a ação dos órgãos ambientais na repressão às práticas tradicionais como um elemento importante no abandono da atividade agrícola.

\footnotetext{
${ }^{11}$ Pesquisa realizada no âmbito do projeto de pesquisa e extensão: "Sensibilização e promoção de práticas sustentáveis com base na agricultura familiar na Região Serrana do Rio de Janeiro", financiado pela Fundação de Amparo a Pesquisa do Estado do Rio de Janeiro e coordenada por Maria José Carneiro.
} 


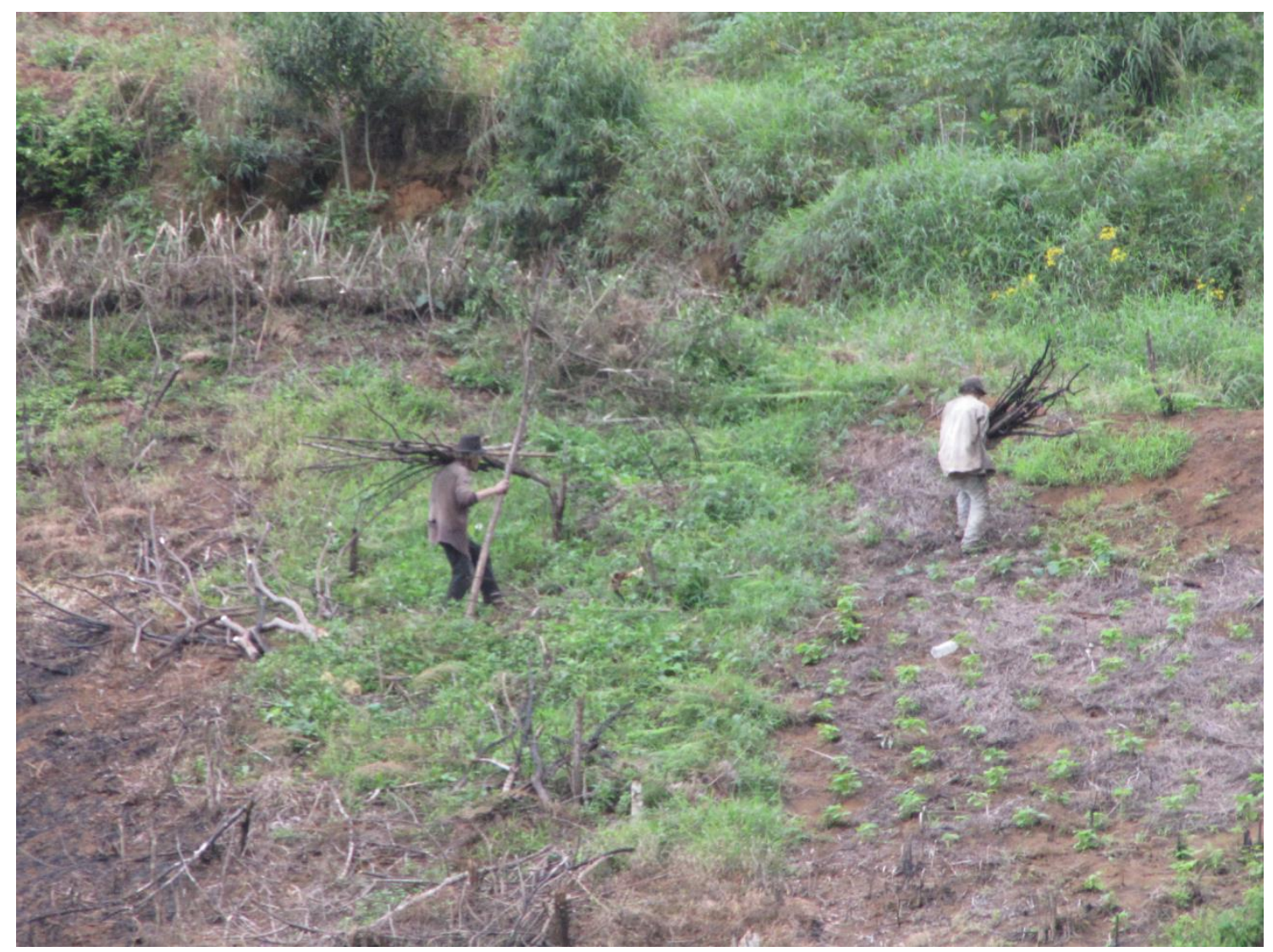

Lavoura Tradicional. Preparando o terreno para o plantio: homens retiram galhos de arbustos após queimada. São Pedro da Serra, 2009. Foto de Maria José Carneiro.

\subsection{Agricultura e "meio ambiente": saberes, práticas e fiscalização}

A partir da década de 1990 observou-se um acirramento da fiscalização ambiental na região que resultou na intensificação da aplicação de multas aos pequenos agricultores, muitas vezes acompanhada de uma ação agressiva e autoritária dos órgãos de controle ambiental, como registra Sá Rego (2008), a partir de relatos da população local. Essa repressão, que já vinha ocorrendo desde o final dos anos 1990, radicalizou-se com a implantação da Área de Proteção Ambiental Estadual de Macaé de Cima em meados de 2000 desencadeando conflitos com a população local, principalmente com os agricultores e proprietários fundiários, resultando em "efeitos contrários aos desejados, pois provocaram rejeição e resistências à temática ambiental” (Rego, 2008: 97).

A principal queixa se referia à proibição do corte da capoeira e da queimada dos galhos e raízes, necessárias quando se desenvolve o manejo do "pousio". Com esse impedimento a área cultivada fica restrita já que não se pode mais esperar o mato crescer para depois cortá-lo: "a terra é cada vez menor, pois onde o mato vem já não dá 
pra fazer mais nada". Os agricultores consideram-se que essa repressão diminuiu muito o exercício da agricultura e avaliam que a situação dos agricultores "Piorou de mais da conta, por isso vai parar. Vai parar porque não dá mais para queimar, nem roçar nada". Só permanecem aqueles que têm recursos para comprar os fertilizantes químicos, cujo uso aumentou muito nos últimos anos. Paradoxalmente, o órgão de conservação ambiental não se preocupa com a poluição do lençol freático e rios pelo uso excessivo de agrotóxico e nem com os prejuízos causados na saúde dos produtores.

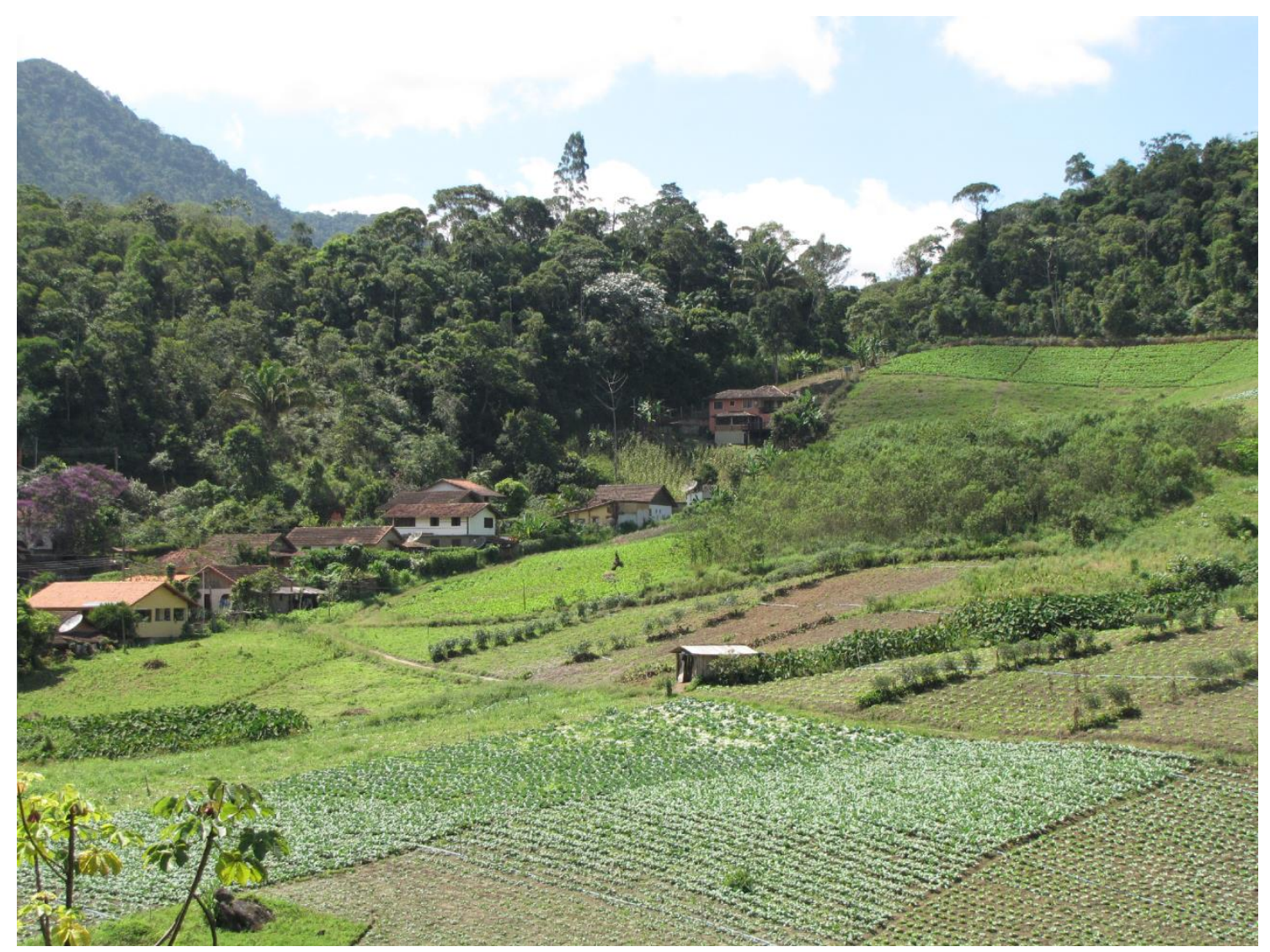

Área de lavoura com diferentes tipos de plantação. No segundo plano, ao centro da foto à direita, vê-se uma pequena área em pousio ocupada por vegetação ("macega"). Ao fundo e na lateral esquerda observam-se áreas de capoeira em estado avançado (reserva) e casas de moradores e de veraneio. São Pedro da Serra, 2009. Foto de Maria José Carneiro.

Essa nova lógica de uso do território incide diretamente sobre a auto-percepção dos agricultores e demais moradores sobre sua localidade. Considera-se que a paisagem foi muito alterada como resultado da repressão à agricultura "tradicional". Interrogado sobre as mudanças nos últimos 30 anos, um agricultor responde: "Mudou muito. (...). 
Esses morros aí... isso era tudo lavoura". Agora essa paisagem dá lugar à mata e às casas secundárias do pessoal que vem das grandes cidades para "curtir a natureza".

Contudo, cabe uma ressalva em relação ao prognóstico sobre o fim da agricultura na região. Considerando o processo de intensificação da produção, podemos inferir que apesar da diminuição na área agricultável, tenha ocorrido uma expressiva elevação de produtividade. Há menos agricultores produtivos mas os que estão na ativa são mais eficazes em termos quantitativo devido às inovações tecnológicas aplicadas. Os agricultores destacam o fato de que estas melhorias nos recursos tecnológicos de produção possibilitaram uma expressiva elevação de produtividade, compensando, em parte, as restrições do espaço de produção agrícola pela Legislação Ambiental.

O pousio é legalizado pela Lei da Mata Atlântica, onde a liberação deste manejo está vinculada a altura da vegetação e sua limitação a espaços já destinados a produção agrícola, não podendo avançar sobre vegetação nativa. Entretanto, no Estado do Rio de Janeiro essa prática, seguida pela queimada, é inviabilizada pelas restrições da legislação ambiental estadual que a consideram prejudicial à regeneração da mata.

Em contraposição a essa compreensão, alguns pesquisadores tem demonstrado a sustentabilidade deste manejo, nos últimos anos. Em sua tese de doutoramento, Queiroz (2007) constatou, a partir de pesquisa empírica no distrito de São Pedro da Serra, que:

o manejo de pousio é o mais apropriado, pois regenera as propriedades físicas e químicas do solo, dando os subsídios necessários para a sua boa utilização agrícola, além de não necessitar da utilização intensa de agrotóxicos, evitando deste modo, a possível contaminação dos mananciais hídricos (2007: 97).

Frente ao uso do fogo, o autor destaca, ainda, que: "as cinzas servem de adubo para terra, fornecendo nutrientes ao solo" (Queiroz, 2007: 61). Porém essa interpretação ainda é bastante controversa no meio acadêmico. 


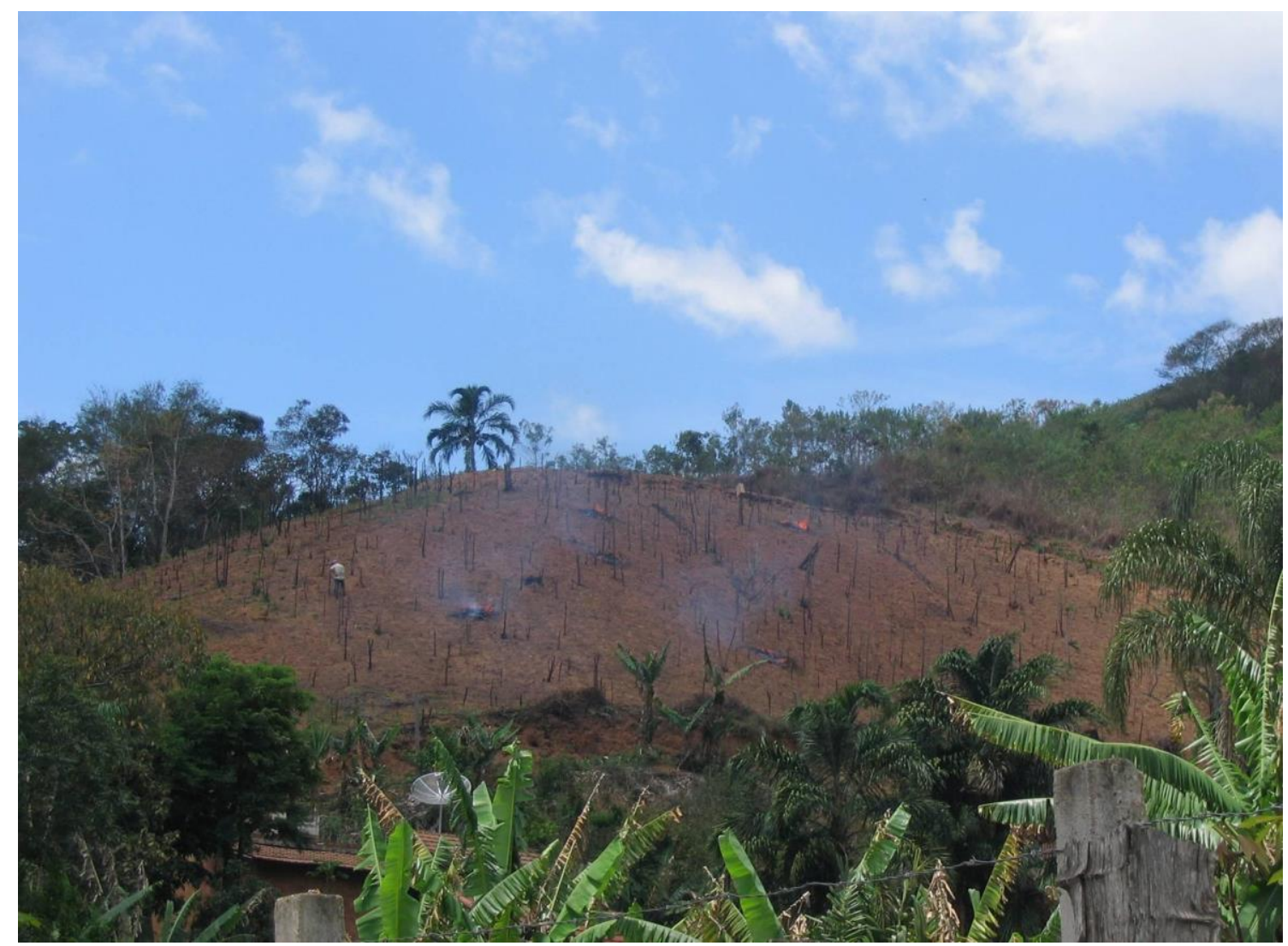

Queimada para preparo da terra para lavoura. Foto de Maria Jose Carneiro. São Pedro da Serra, 2009.

Estas questões também têm motivado questionamentos por parte dos agricultores sobre o conhecimento dos técnicos ambientais acerca da sustentabilidade. Na defesa de suas práticas tradicionais, argumentam que se ainda há mata a ser preservada na região, isso se deve a seus antepassados que souberam mantê-las por quase dois séculos. Explicam que seus ancestrais sempre deixavam diversas brotações no momento em que realizavam o corte da vegetação e a posterior queimada no preparo para da terra para a lavoura, o que garantia a recomposição da vegetação. Entretanto, com a proibição da prática de corte da capoeira em crescimento adiantado (o que faz que seja classificada "mata em regeneração"), como também da queimada dos detritos restantes, os agricultores não deixam mais estas brotações, o que contribui para a diminuição da fertilidade do solo em que é realizado o pousio. Hoje, além de não deixarem esses brotos, o pousio da terra não pode durar mais de 2 ou 3 anos com risco da vegetação já atingir um tamanho em que o corte é proibido. Com isso observa-se um efeito perverso do controle ambiental que acaba por provocar a perda de fertilidade do solo e o aumento 
do uso de agroquímicos que poluem o lençol freático e causa danos à saúde dos produtores.

Nas disputas com o INEA (Instituto Estadual do Meio Ambiente) os agricultores reclamam da percepção ambiental que não leva em consideração os saberes da população local sobre o meio ambiente, salientando o fato de que, se a região é preservada hoje, isso se deve aos seus antepassados que souberam manejá-la de forma a preservar a mata, praticado o manejo de pousio e com uso controlado do fogo. Nessa direção, uma das principais reivindicações dos agricultores de São Pedro da Serra e Lumiar, no contexto atual em que se encontram, é a necessidade de serem valorizados os saberes sobre a produção e o modo de vida construído historicamente na região, como expressa um agricultor:

Se você quer ter uma lavoura com saúde, uma lavoura fértil, você tem de ter o sistema de pousio. Por que? Porque passou de dois anos em uma área de alto declive, você passou a produzir menos, porque o terreno cansa. Por quê? Porque há erosão. A erosão é a enxurrada que arrasta a terra boa para baixo, vai ter de ter muitos anos para recompor. Com dois anos, o terreno ainda absorve água, porque existem muitas raízes daquele mato que você retirou há dois anos. A partir de dois anos começa a apodrecer as raízes e já começa a nascer muito capim. Em vez de absorver a água, não absorve porque não tem mais muitas raízes para absorver a água, aí começa a escorrer tudo prá baixo. Por isso que precisa do sistema de pousio para ter uma boa produção, prá ter raízes prá absorver a água da chuva. (...) Tem terreno que com dois anos você já pode usar de novo porque é muito fértil. Mas tem áreas que o terreno é mais pobre, vai ter de deixar uns 4 ou 5 anos.

\section{Considerações finais}

Com o presente artigo pretendemos contribuir para a reflexão a respeito da formulação e implementação de políticas públicas voltadas para o desenvolvimento sustentável da agricultura familiar de montanha. Assim, enfatizamos a importância e a necessidade do aprofundamento de pesquisas sobre o modo de vida construído historicamente por esse segmento da população, evitando generalizações simplificadoras que não levam em conta a sua especificidade sociocultural e o contexto socioambiental. Evidencia-se a necessidade de se estabelecer uma interface profícua entre os saberes locais historicamente construídos e novas perspectivas de desenvolvimento sustentável integradas às práticas de conservação ambiental para a região, que só ganharão eco se forem expressas em termos que sejam compreensíveis e acessíveis pela população local. 
Pesquisas que caminhem nessa direção são consideradas, aqui, como essenciais para a compreensão das tendências de longo prazo através das quais foi sendo estruturada e consolidada historicamente uma determinada dinâmica de reprodução social da agricultura familiar. A partir desta perspectiva, percebemos como o modo de vida desse segmento da população rural, sustentado na relação produtiva com a terra, foi sendo reconfigurado, especialmente nas últimas três décadas, quando a dinamização do setor de turismo, associada à implantação de uma APA modificou a relação com a terra, desencadeou conflitos e abriu novas alternativas de trabalho. Vimos também como um modo de vida constituído ao longo de 2 séculos de ocupação de um território, com base na agricultura, foi se modificando e se adaptando aos novos constrangimentos impostos seja pelo ritmo do trabalho assalariado, seja pelas "comodidades" de uma economia cada vez mais comandada pelas trocas mercantis. Paralelamente, observou-se uma convivência de forças contraditórias em que de um lado, a implementação da legislação ambiental visando a conservação da Mata Atlântica impôs restrições ao modo de uso tradicional da terra - o sistema de pousio - provocando um aumento considerável e arriscado do uso de agrotóxicos, por outro, o estímulo ao desenvolvimento sustentável da agricultura familiar aponta na direção do resgate e valorização desse tipo de manejo.

A ampliação da gama de capacidades dos atores sociais nesta região, no sentido de alargar seu direito de poderem levar a vida que desejam e contribuir em seu progresso econômico, reforça a sua condição de agricultores pluriativos, já que a agricultura não se coloca mais como atividade viável no sustento exclusivo das famílias. Mas, importante também considerar a dimensão multifuncional dessa agricultura que, para além da produção de alimentos, presta importantes serviços à sociedade seja na preservação da floresta ao longo desse período de ocupação do território, seja na manutenção dos recursos hídricos e, principalmente, na persistência de uma sociedade viva com um tecido social denso de sociabilidade e de manifestações culturais.

Contudo, entendemos que a principal ameaça à ampliação e sustentação destas possibilidades está na instabilidade à qual a agricultura familiar desta região foi submetida nas últimas décadas. Ameaça essa que se expressa não só no fim de um meio de vida mas também no desaparecimento de um modo de vida construído com muito esforço desde a chegada dos primeiros migrantes que atravessaram o Atlântico com sua famílias no inicio do século XIX em busca de melhores condições de vida em alternativa às adversidades pela passavam em seus países de origem. Nesse contexto, 
entende-se que a manutenção da atividade agrícola tem um significado para eles que vai além da dimensão econômica. Sobre ela se sustenta um modo de vida, uma identidade social e a memória sobre os antepassados.

Por fim, salientamos que o desenvolvimento sustentável desta região passa, necessariamente, pelo estímulo ao diálogo entre as diferentes forças sociais presentes nesse território, de modo a possibilitar o surgimento de alternativas enraizadas nos saberes historicamente construídos e nas potencialidades engendradas pelas novas dinâmicas econômicas, sociais e culturais.

\section{Referências}

ARAÚJO, João Raimundo de; MAYER, Jorge Miguel. Teia serrana: formação histórica de Nova Friburgo. Rio de Janeiro: Editora ao Livro Técnico, 2003.

BRANDÃO, Carlos Rodrigues. Plantar, colher, comer: um estudo sobre o campesinato goiano. Rio de Janeiro: Graal, 1981.

CANDIDO, Antônio. (1954). Os Parceiros do Rio Bonito: estudo sobre o caipira paulista e a transformação dos seus meios de vida. São Paulo: Trinta e Quatro, 1997.

CARNEIRO, M.J. Descendentes de Suíços e Alemães de Nova Friburgo: de 'colonos' a 'jardineiros da natureza'. In: GOMES, Angela de Castro. (Org.). Historia de imigrantes e de imigração no Rio de Janeiro. 1ed. Rio de Janeiro: 7 Letras, 2000.

CARNEIRO, Maria José (Coord). Ruralidades contemporâneas: modos de viver e pensar o rural na sociedade brasileira. Rio de Janeiro: Mauad X; FAPERJ, 2012.

CARNEIRO, Maria José; TEIXEIRA, Vanessa Lopes. Pluriatividade, Novas Ruralidades e Identidades Sociais. In: Campanhola, C. e Graziano da Silva, J. (Orgs.). O novo rural brasileiro: novas ruralidades e urbanização. 21ed. Brasília: Embrapa Informação Tecnológica, 2004.

CASTRO, Hebe de Mattos. Ao Sul da História. Rio de Janeiro, Ed. Brasiliense, 1987.

CHAMBERS, Robert; CONWAY, Gordon R. Sustainable Rural Livelihoods: practical concepts for the 21st century. IDS discussion paper. Brighton, England: Institute of Development Studies, 1992.

COSTA, Julio Roberto Pinto Ferreira da; TURETTA, Ana Paula Dias, DONAGEMMA, Guilherme Kangussu; BALIEIRO, Fabiano de Carvalho. A agricultura no município de Bom Jardim, RJ: Entre a sustentabilidade e a precarização do trabalho. In: Seminário Nacional de Sociologia e Política, 2, 2010, Curitiba. Tendências e desafios contemporâneos: anais. Curitiba: UFPR, 2010.

COSTA, Karla Karina Santos da; SILVA, Gisele; SALGADO, Jamile Constança R. S. S.; BERTOLINO, Ana Valéria A.; BARROS, Ana Angélica Monteiro de. Fitossociologia, produção mensal e retenção hídrica da serrapilheira em fragmento de Mata Atlântica - São Pedro da Serra. Anais do XIII Simpósio Brasileiro de Geografia Física Aplicada, Viçosa, v. 13, p. 162-163, 2009.

CURIÓ, Pedro. Como surgiu Nova Friburgo. RJ., s/ed. 1974.

DIEGUES, Antonio Carlos. O Mito Moderno da Natureza Intocada. São Paulo, Hucitec, 2001.

ELLIS, Frank. Rural livelihoods and diversity in developing countries. Oxford: Oxford University Press, 2000.

FRAGOSO, João, L.R. A nobreza vive em bandos: a economia política das melhores famílias da terra do Rio de Janeiro, século XVII. Tempo. Revista do Departamento de História da UFF, Niterói, v. 8, n.15, p. 11-35, 2003. 
INSTITUTO BRASILEIRO DE GEOGRAFIA E ESTATISTICA - IBGE. Enciclopédia dos Municipios Brasileiros. Volume XXII. Rio de Janeiro: IBGE, 1959.

MUAZE, Mariana. As Memórias da Viscondessa. Família e poder no Brasil Império. Rio de Janeiro: Jorge Zahar Editor, 2008.

NICOLIN, Martin. A gênese de Nova Friburgo - Emigração e Colonização suíça no Brasil. Rio de Janeiro: Fundação Biblioteca Nacional, 1995.

PETRONE, M. Thereza Scroer. O imigrante e a pequena propriedade (1824-1930). São Paulo, Brasiliense, 1982.

QUEIROZ, Joedy Patrícia Cruz. Estudo sobre a distribuição do herbicida 2,4-D nos solos da Região de São Pedro da Serra RJ e sua importância ambiental. Tese de Doutorado. DCMM, PUC-Rio. 2007.

SCHNEIDER, Sérgio; SOUZA, Marcelino de; PEREIRA, Márcio de Araújo. Meios de vida e livelihoods: aproximações e diferenças conceituais. Revista IDeAS - Interfaces em Desenvolvimento, Agricultura e Sociedade, Rio de Janeiro - RJ, v.4, n.1, p.203-224, jun./jul. 2010.

REGO, Virgina Vilas Boas Sá. Paraísos perdidos ou preservados: a conquista da cidadania em áreas de proteção ambiental. In.: Anais do Encontro Nacional da ANPAS. GT - Mudanças ambientais globais: a contribuição da ANPAS ao debate, 6, Brasília, 2008.

SCOONES, Ian. Livelihoods perspectives and rural development, Journal of Peasant Studies, 36:1, 171-196, 2009.

SEN, Amartya. Desenvolvimento como liberdade. São Paulo: Companhia das Letras, p. 463, 2010.

TEIXEIRA, Vanessa Lopes. Pluriatividade e agricultura familiar na região serrana do estado do Rio de Janeiro. Dissertação de Mestrado: Programa de Pós-Graduação de Ciências Sociais em Desenvolvimento, Agricultura e Sociedade, UFRRJ Seropédica: UFRRJ, 1998.

TEIXEIRA, Vanessa Lopes. O rural não agrícola fluminense. Boletim de Economia Fluminense, Niterói, RJ, 01 abr. 2001.

TEIXEIRA, Vanessa Lopes. Ocupação e Renda de Famílias Rurais da Região Serrana do Estado do Rio de Janeiro. In: Clayton Campanhola e José Graziano da Silva. (Org.). O novo rural brasileiro: rendas das famílias rurais. 21 ed. Brasília: Embrapa informação tecnológica, 2004.

Recebido em: 31/10/2015.

Aprovado em: 28/03/2016. 